\title{
A presença de escravos carmelitas na Fazenda Capão Alto, no Paraná: questões historiográficas
}

\section{The presence of Carmelites slaves in Capão Alto farm, Paraná: historiographical questions}

\section{Josélia Maria Loyola de Oliveira Gomes}

Universidade Estadual de Ponta Crossa

\section{Resumo}

$\mathrm{O}$ artigo tem como objetivo coligir questões da historiografia regional relacionadas aos escravos carmelitas da Fazenda Capão Alto (PR), apontar ações cooperativas entre os escravos carmelitas de Castro (PR), contextualizar o arrendamento e a posterior venda dos cativos para o interior de São Paulo e indicar as comunidades de remanescentes de quilombos (CRQs) na região de Castro (PR). O referencial direcionou-se para artigos, dissertações, teses e livros que se valeram de documentos compostos por listas nominativas de habitantes, registros de batismos e casamentos, processos judiciais e cartoriais, jornais e correspondências oficiais. Os escravos carmelitas administraram a Fazenda Capão Alto entre 1770 e 1867. O arrendamento dos escravos, em 1864, causou revolta e resistência. A saída definitiva dos cativos para o interior de São Paulo foi dividida em dois grupos, provavelmente em 1867. No primeiro grupo, 50 escravos foram levados para trabalhar na construção da ferrovia que ligava a cidade de Jundiaí a Campinas. No segundo grupo, foram comercializados 186 escravos da Fazenda Capão Alto ao comendador Francisco Teixeira Vilela, de Campinas (SP). Das comunidades de remanescentes de quilombos (CRQs), na região de Castro (PR), três apresentam descendência de escravos fugidos da Fazenda Capão Alto.

Palavras-chave: Escravidão; Escravos carmelitas; Fazenda Capão Alto (PR); Fazendas Históricas; Comunidades de Remanescentes de Quilombos.

\section{Abstract}

This article has the aim to collect inquiries from the regional historiography interconnected to the Carmelite slaves from Fazenda Capão Alto (PR), to point out cooperative actions among Carmelite slaves in Castro (PR), to contextualize theleasingand future sale of the captives to São Paulo countryside and to indicate the communities of remaining slaves of quilombos - the so-called slave campsites - in Castro (PR) region. This study has directed to articles, essays, theses, and books which took advantage of documents including list of names of the inhabitants, baptisms and weddings recordings, judicial and notarial processes, official mail and newspapers. The Carmelites slaves managed Fazenda Capão Alto from 1770 to 1867. The slaves leasing, in 1864, caused uprising and resistance. The definitive exit of the captives towards São Paulo countryside has been divided in two groups, most likely in 1867. In the first group, fifty slaves were taken to work in a new railway which would connect Jundiaí to Campinas, both in the state of São Paulo. In the second group, 186 slaves from Fazenda Capão Alto were sold to commendator Francisco Teixeira Vilela from Campinas (SP). From the communities of remaining slaves of quilombos - the so-called slave campsites - in Castro (PR) region, three of them present descent of runaway slaves of Fazenda CapãoAlto.

Keywords: Slavery; Carmelite slaves; Fazenda Capão Alto (PR); Historical Farms Communities of remaining slaves of quilombos. 


\section{Notas de Pesquisa}

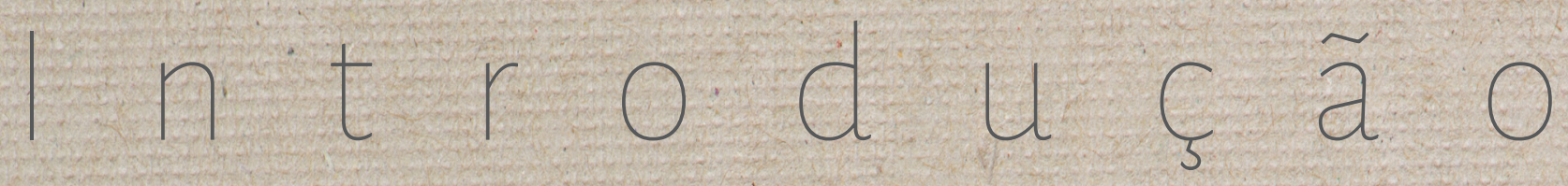

\section{A}

s notas de pesquisa aqui apresentadas foram extraídas do relatório do projeto cultural Arqueologia e historiografia da Fazenda Capão Alto, um processo de extroversão, aprovado pelo $\mathrm{Mi}$ nistério da Cultura, através da Lei Rouanet, e com execução entre 2014 e 2016. Elaborado pelo Núcleo de Mídia e Conhecimento (NMC), de Curitiba (PR), em parceria com o proprietário da fazenda, Koob Petter, tal projeto teve entre seus objetivos específicos dois aspectos que se destacaram. Primeiramente, a implementação de um projeto preliminar, arqueológico e histórico, que antecedeu as atividades executivas de arqueologia, de restauração para ampliação do conhecimento sobre o bem cultural em questão. Em segundo lugar, a execução de um plano de comunicação com ênfase na educação patrimonial e na difusão dos serviços disponíveis na Fazenda Capão Alto'.

A Fazenda Capão Alto está ligada à presença dos carmelitas e escravos, ao tropeirismo e aos estudos de experimentação agropecuária, em especial a partir da década de 1980. Atualmente, suas principais atividades se direcionam às atividades de dimensão didático-pedagógica, como a visitação à casa-sede e seu entorno, com área de campos e mata nativa, ou as exposições culturais e arqueológicas ali organizadas.

Desde 2001, a Fazenda Capão Alto transformou-se em espaço aberto à visitação dada sua relevância turística regional. Seus proprietários planejam nova restauração da casa-sede e de seu entorno, elaboração de um plano interpretativo de visitaçáo e de comunicação para o espaço cultural, e execução de melhoramentos na infraestrutura para o compartilhamento ao público visitante.

\section{A presença de escravos carmelitas na Fazenda Capão Alto}

Entre as primeiras referências do período colonial que remetem à região dos Campos Cerais, no estado do Paraná, e especificamente à área relativa da Fazenda Capão Alto, se menciona

1 A Fazenda Capão Alto foi tombada em, 26 de novembro de 1983 , conforme inscrição no Livro Tombo II, $n^{\circ}$. $80, p^{2}$ rocesso $n^{\circ}$. 82/81, da Secretaria de Estado da Cultura/Coordenadoria do Patrimônio Cultural do Paraná. Apesar disso, ainda busca apoio para seu reconhecimento em âmbito nacional. 
a concessão da sesmaria na paragem do lapó para Pedro Taques de Almeida e familiares, em 1704. No ano de 1751, a Fazenda Capão Alto foi comprada de José Goes de Moraes pelo Frei João de Santa Izabel, seguida de posse judicial ao procurador da Ordem Carmelita de São Paulo. Posteriormente, o crescimento da futura vila de Castro e a reforma da Ordem Carmelita de 1785-7800² contribuíram para que os freis carmelitas se retirassem para São Paulo ou Rio de Janeiro. Antes mesmo disso, a partir de 1770, a Fazenda Cápão Alto passou a ser administrada por seus escravos (ROSAS, 1972, p. 19 e p. 64) (PARANÁ, 1985, p. 26), que até 1864 constituíram uma comunidade independente.

Em 1785, com a reforma carmelita, o convento do Rio de Janeiro, sede da Província do Carmo e casa capitular, pediu aos seus conventos que realizassem inventários de seus bens. À Província do Carmo do Rio de Janeiro pertenciam os conventos do Rio de Janeiro, São Paulo, Santos, Angra dos Reis, Mogi das Cruzes, Vitória, além dos hospícios de Itu e Lisboa. O convento do Carmo de São Paulo possuía seis fazendas e 18 moradas de casas (SILVA, 2013, p. 147).

Quanto às Fazendas Capão Alto e Fundão, consta um pedido encaminhado do Governador da Capitania ao Ouvidor de Paranaguá, em 15 de julho de 1785 , sobre a demora da execução da ordem encaminhada em março, e sobre a necessidade de brevidade para incorporar os ditos inventários, devendo ficar como depositários os administradores da fazenda (OFíCIO, 1961, p. 165). Infelizmente, nos arquivos pesquisados, não se constatou resposta ou outra ação quanto ao pedido formulado.

Mesmo longe, os carmelitas observaram alguns cuidados com a Fazenda Capão Alto e seus bens. Um exemplo a citar é o requerimento, registrado como auto de violência, do Convento do Carmo de São Paulo ao Ouvidor de Paranaguá, em $1^{\circ}$ de março de 1789 , consultado em cópia de sua forma original e manuscrita, juntamente com um mapa, quanto à delimitação das servidões. No requerimento, constava a descrição da servidão dada a dois vizinhos de fundos da Fazenda Capão Alto, para que passassem pelo caminho do Maracanã que atravessava a fazenda, a oeste. A queixa se remete aos vizinhos que, não contentes com a servidão recebida, abriram nova servidão imprópria, cortando ao meio a Fazenda Capão Alto, local em que os religiosos possuíam parte de sua criação, especialmente potreiros, deixando cercas devassas, e ocasionando extravios de animais pelos campos abertos. O convento menciona, nesse requerimen-

2 A partir de 1780 , a Coroa demonstrou pouca tolerância com as ordens religiosas, dadas as desordens e comportamentos considerados abusivos. De 1785 a 1800, houve a reforma da Província Carmelita Fluminense. Em meados do século XIX, as ordens religiosas brasileiras sofreram impactos da política antimonástiça do governo, ocasionados pela presença do ultramontanismo e reforma do clero. A partir do Aviso Circular de 1855 do Ministério da Justiça, ficou proibido aos conventos das ordens religiosas a aceitação de novos noviços, até que fossem resolvidas pendências com a Santa Fé. De 1865 até 1899 , a Ordem do Carmo esteve por determinação do governo imperial subjugada ao Regime de Visitadores Apostólicos. Foi um período no qual a Igreja católica brasileira passou por uma reorientação (WERNET, 1997, p. 127). 
to, que tentou obviar seus prejuízos, contentando-se a reformar cercas para aviventar os vassalos. Em geral, o requerimento visava embaraçar os prejuízos, de modo a sujeitar os vizinhos a trilhar pelas antigas servidões. Junto ao referido requerimento, consta certidão do Corregedor de Paranaguá ao Juiz Ordinário da Vila de Castro para atender ao pedido e fazer cessar a violência respectiva apresentada (AUTO DE VIOLÊNCIA, 1798, p. 1-3).

O Ensaio d'um Quadro Estatístico da Província de S. Paulo em 1836, organizado por Daniel Pedro Müller (publicado em 1838), apontou para a Vila de Castro (PR) uma população de 6.190 habitantes, sendo 4.503 livres e 1.687 escravos. A população era de 3.172 homens e 3.018 mulheres. Os grupos por idade entre 20 e 39 anos compreendiam um número de 1.138 para a população livre e de 680 para a população escrava. Quanto à instrução, o número de pessoas que sabiam ler e escrever era de 202. Na produção econômica, em geral a população se dedicava à criação de gado de toda a espécie, plantava arroz, milho, feijão e alguma cana de açúcar e preparava farinha de mandioca e erva-mate (BASSANEZI, 1998, p. 166-174 e p. 214).

Para a elaboração das listas nominativas, o território correspondente à Vila de Castro esteve distribuído, inicialmente, em três Companhias de Ordenanças e, a partir de 1818, em seis Companhias (PINTO, 1992, p. 8).

Nas Companhias de Ordenanças da Vila de Castro foram distribuídos os bairros. Alguns apresentaram rápido desenvolvimento devido às atividades de criação, invernagem e comercialização de gado que, ao lado da necessidade da prestação de outros serviços, atuaram como pólo de atração de migrantes (PINTO, 1992, p. 82).

Dentro da perspectiva da historiografia demográfica, a tese de Pinto (1992) privilegiou ol hares para o estudo da Vila de Castro de 1801 a 1830. Em uma das tabelas apresentada pela autora (PINTO, 1992, p. 96), constatou-se que a população de Castro, em 1800, era de 3.400 livres e 947 escravos; em 1806, 3.712 livres e 1.001 escravos; em 1811, 3.764 livres e 1.035 escravos; em 1822, 3.387 livres e 989 escravos; em 1828, 4.520 livres e 1.534 escravos; em 1830, 4.389 livres e 1.469 escravos.

Em contrapartida, em 1825, quanto aos aspectos de produçã́o, os estudos de Cutiérrez (2004, p. 110), no arrolamento das listas nominativas, apontaram um rebanho total para a Vila de Castro com 29.863 cabeças, incluindo gado vacum, cavalar, muar e lanígero. Em termos de produção pecuária, a base central era para o gado vacum; em segundo, o cavalar; em terceiro, o lanígero, e quanto ao muar, apenas dois fazendeiros investiram em 140 cabeças.

Nas listas nominativas de habitantes de Castro, no período de 1801 a 1830 constavam, segundo tese de Pinto (1992), quatro fazendas pertencentes à Ordem de Nossa Senhora do Carmo: Capão Alto, Cunhaporanga, Vassoural e Fundão. As fazendas de propriedade dos religiosos estavam incluídas na categoria de domicílios indeterminados, pois não se especificava quem as administrava. Em 1801, a Fazenda do Capão Alto, a mais importante, era habitada por 56 escravos e 18 agregados. Em 
1830, o número de escravos passou para 118, não apenas como reflexo da fecundidade, mas de uma possível transferência de escravos vindos da Cunhaporanga. De 1801 a 1830, na Fazenda Capão Alto o número médio foi de 81 escravos e de 17 agregados.

Como apontou Pinto (1992), os agregados se constituíram numa camada social flutuante de pessoas livres, que mantiveram junto aos fogos (domicílios) variadas formas de relações, seja por prestação de serviços ou grau de parentesco. Em raras exceções, na documentação referente à Vila de Castro, foram declaradas essas formas de relação. Normalmente, os agregados apresentavam laços de parentesco com os dos fogos ou eram crianças expostas.

Numa rápida análise das listas nominativas, observou-se que as fazendas carmelitas estavam localizadas na $1^{\text {a }}$ Companhia de Ordenança da Vila de Castro, no bairro de Santa Cruz, e que apresentavam flutuações quanto ao número de identificação do domićlio/fogo. Em 1801, as Fazendas Capão Alto e Cunhaporanga estavam no fogo $n^{\circ} .221$ e a Fazenda Fundão no n. ${ }^{\circ} 235$. Em 1803, a Fazenda Capão Alto foi identificada como fogo n. ${ }^{\circ} 201$, a Fazenda Cunhaporanga no n. ${ }^{\circ} 202$. Em 18,04, a Fazenda Capão Alto estava no fogo n. ${ }^{\circ} 222$ e a Fazenda Cunhaporanga no n. ${ }^{\circ} 223$ (LISTAS NOMINATIVAS, 1801-1830).

Diferentemente, quanto ao número de propriedades, os estudos de Cutiérrez (2004), referentes às listas nominativas de 1825 , indicam que a Ordem Terceira de Nossa Senhora do Carmo tinha três fazendas: Capão Alto, Fundão e Cunhaporanga, com um total de 98 escravos, constituindo o maior contingente particular de cativos do Paraná. Na Fazenda Capão Alto, o número de cativos era 68. Quanto à quantidade de animais, as fazendas carmelitas possuíam 2.120 cabeças de gado vacum. As fazendas foram administradas pelo capelão ou administradores cativos.

Para o estudo referente a 1825, Gutiérrez (2004) utilizou o cruzamento de dados de listas nominativas com o inventário dos bens rústicos de 1818, um cadastro de terras, para a obtenção de informações quanto à dimensão das áreas. O autor destaca que as fazendas carmelitas da Vila de Castro se dedicavam à pecuária e tinham as respectivas áreas: Capão Alto com 16.335 hectares, Fundão com 9.801 hectares e Cunhaporanga com 3.267 hectares. A extensão das três não era das maiores da região e o número de escravos se repartia basicamente entre a primeira e a última fazenda.

A Fazenda do Fundão era dedicada às invernadas de tropas em trânsito, que se dirigiam a Sorocaba, oriundas do Rio Grande do Sul. Em 1825, consta que a Fazenda do Fundão não tinha gado próprio nem produção agrícola, sendo administrada por sete escravos. Foi considerada a única fazenda de Castro e Ponta Grossa reservada a esse uso exclusivo, que se ampliou após 1870, quando a criação paranaense perdeu em importância e rentabilidade para o aluguel de pastos e a engorda do gado sulino (CUTIÉRREZ, 2004).

Desse universo referente aos habitantes da Fazenda Capão Alto, a pesquisa de Mello (2004) vem somar.pontos interessantes ao privilegiar as listas nominativas dos anos de 1824, 1829 e 1835, con- 
frontando-as com dados retirados de transcrições dos Assentos de Casamentos (1793-1824) e dos Registros de Batismo (1801-1817) referentes à população cativa de Castro.

Entre suas argumentações, Mello (2004, p. 120-125) apontou que o absenteísmo dos proprietários carmelitas permitiu aos escravos da Fazenda Capão Alto possibilidades para que se organizassem "mais à sua maneira", formando famílias e estabelecendo nọrmas de convivência. Talvez por esse motivo não ousassem sair das terras, já que as possiveis punições às desobediências das normas preestabelecidas eram menos rígidas. Outro fator possível foram as uniões duradouras estabelecidas e a multiplicação de rebentos (filhos). Os escravos se casaram e mantiveram famílias. A consolidação de famílias pode ter contribuído tanto para atenuar as diferenças como para proporcionar inserção na comunidade. Possivelmente as uniões conjugais tiveram alguma característica peculiar frente àquelas em que os cativos estavam sob os olhares de seus senhores. Na Fazenda Capão Alto, os trabalhos eram executados pelos próprios escravos, anteriormente instruídos e disciplinados pelos carmelitas. Eram administrados por um cativo escolhido. Ser o escolhido concedia certa posição de destaque na hierarquia social interna. Provavelmente, para o escolhido cativo, manter essa posição não tenha sido uma tarefa das mais simples.

Mesmo diante das incertezas das fontes transcritas das fichas de batismo, Mello (2004) identificou e confrontou os dados com segurança em apenas 10 casais reconhecidos nas Listas Nominativas de 1824, relativos aos cativos da Vila de Castro. Para ilustrar as condições estáveis familiares entre os cativos da Fazenda Capão Alto, a pesquisadora cita o exemplo do casal de escravos Manoel e Matildes, que, em 1824, foi responsável por zelar 67 escravos.

Das Listas Nominativas de 1829, Mello (2004) constatou que os cativos da Fazenda Capão Alto foram administrados pelo escravo-capataz Pedro, de 40 anos, casado com a negra Felizarda, ambos responsáveis por 119 cativos. Dentre esses, 53 estavam ligados por laços de parentesco. Os cativos estavam distribuídos em 10 casais, acompanhados ou não por filhos, 3 mães solteiras, 14 viúvos e viúvas, muitas vezes rodeados por seus filhos adultos. Dos censos ou Listas Nominativas de 1835 , Mello (2004) afirmou que a Fazenda Capão Alto abrigava 99 escravos, constituindo-se na maiorescravaria absenteísta da Vila de Castro.

Nas terras da fazenda, os escravos foram disciplinados para o trabalho e pela religião dos frades carmelitas e tinham grande devoção à Nossa Senhora do Carmo - a Sinhara. Desde a saída dos carmelitas, o "administrador" era eleito semanalmente entre os escravos para supervisionar os trabaIhos. Ao eleito cabia interpretar as orientações da Sinhara. Vendiam o que fọsse possível na Vila de Castro para garantir o sustento da fazenda (PARANÁ, 1985, p. 27; CAZETA, 1886, p. 1).

Quanto ao cotidiano da Fazenda Capão Alto, a tese de Molina (2006) assinalou que a documentação interna da Ordem do Carmo e os relatórios não evidenciaram detalhes sobre as vivências em razão da fragmentação das fontes produzidas no contexto de restrição legislativa imperial aos car- 
melitas e o subsequente colapso na administração ${ }^{3}$. Como segundo aspecto sobre o cotidiano dos escravos, Molina (2006) ainda destacou que o grau de autonomia escrava era decorrente do fato de os frades estarem distantes e ocupados em rebater os constantes ataques do governo e da Província Carmelita sobre seus patrimônios ${ }^{4}$.

Das pesquisas em registros paroquiais, o estudo de Oliveira (2013) apontou que, na década de 1840, o capataz Pedro era o responsável por fiscalizar as atividades na Fazenda Capão Alto. Entre os anos de 1796 e 1863, foram registrados 34 casamentos. Dos anos de 1799 a 1857, foram batizadas 171 crianças. Os cativos estabeleceram laços de compadrio que se estenderam para fora dos limites da Fazenda Capão Alto, com escravos das outras fazendas pertencentes à Ordem Carmelita, Cunhaporanga e Vassoural.

\section{Entre suas argumentações, Oliveira (2013) mencionou que na fazenda Capão Alto viviam agre-} gados, pessoas libertas e livres. Como exemplo, citou que, em fevereiro de 1805 , recebeu os santos óleos "o forro Constantino, filho dos libertos Nicomedy e sua mulher Antonia, tendo como padrinhos Francisco Duarte e sua mulher Bibiana Rodrigues, todos forros e agregados da fazenda do Capão Alto" (OLIVEIRA, 2013, p. 161-162). Até 1860, a comunidade de cativos permaneceu sossegada em seu cotidiano na Fazenda Capão Alto, integrada nesse período por 125 homens e 111 mulheres. Mais de 50\% dos escravos tinham idades de 0 a 14 anos.

3 Para sua pesquisa, Molina (2006) coletou dados em inúmeros arquivos brasileiros. Entre suas considerações, comentou que, durante o século XIX, a documentação produzida nos conventos carmelitas era remetida para a casa principal da Corte e, no século XX, com a chegada dos frades estrangeiros, ingleses e holandeses, ocorreu a centralização dos registros no Convento do Rio de Janeiro. Na década de 1950, em virtude de um incêndio grande parte da documentação foi perdida. Parte do que restou foi cedida ao Arquivo Nacional, no Rio de Janeiro (RJ), e outra encaminhada ao Arquivo Particular do Carmo (APCBH), no convento do Carmo, em Belo Horizonte (MG). Em complementação, os estudos de Pedras (2000) no Arquivo Particular do Carmo em Belo Horizonte indicaram a existência de fontes primárias ainda pouco exploradas. Somente a partir da década de 1970 o governo da Ordem Carmelita se preocupou com a conservação dos diversos arquivos dos conventos brasileiros e buscou a centralização de suas fontes informativas.

4 Na Ordem do Carmo de São Paulo, no século XVIII, viviam à época quatorze religiosos e um leigo. O número de escravos chegou a 431. Os carmelitas foram proprietários de fazendas em Castro (Capão Alto), Sorocamirim, Biacica, Caguaçu e outras nas terras de Santos, Moji das Cruzes e Itu. No século XIX, em 1836, o Convento do Carmo de São Paulo, conforme estudo de Daniel Pedro Müller (apud BRUNO, 1953, p. 767; ARROYO, 1966, p. 67) era habitado por dois religiosos apesar possuía trinta e uma casas de aluguel, seis estabelecimentos de agricultura, uma fazenda para criação e mais de cento e trinta escravos; de onde proviam seus rendimentos. Desde 1760, inúmeros instrumentos legislativ́os visavam a subjugação e enquadramento da Igreja aos desígnios do Estado. A partir de 1770, surgiram as "preocupações pombalinas voltadas não só em relação aos bens da igreja quanto ao endividamento dos conventos e mosteiros, as consequências materiais e morais a isso atribuídas" (SILVA, 2013, p. 145). O clero passou a ser visado pelo governo. No decênio seguinte, o governo do. Estado do Brasil, com o vice-rei Luís de Vasconcelos e Sousa, demonstrou pouca tolerância com as ordens religiosas, dadas as desordens e os comportamentos considerados abusivos por parte dos religiosos da capitania. Interviu entre os franciscanos da Imaculada Conceição em 1780 e entre os capuchinhos italianos em 1781 (SILVA, 2013, p. 145-152). Em novembro de 1783, sobre as mazelas dos carmelitas fluminenses, o vice-rei apresentou extensa queixa contra os religiosos à corte, comunicando um quadro de déficit financeiro entre 1771 e 1783, além de uma generalizada quebra do voto de pobreza. Em 1784, D. Maria I nomeou D. José Joaquim Justiniano Mascarenhas Castelo Branco como visitador e reformador apostólico da Província Carmelita fluminense "com amplos poderes". O reformador assumiu a gerência do patrimônio da província carmelita de 1785 a 1800 . A linha-mestra fọi severa e visava a reintrodução da mendicância entre os frades, uma ação incidente para a racionalização quanto ao uso das propriedades para a quitação das dívidas. No primeiro aspecto, as medidas abrangeram a venda e o arrendamento de propriedades. Ao final dessa política de austeridade, o presidente provincial relatou que, exceto a casa capitular, a do Rio de Janeiro, as outras casas encontravam-se desempenhadas. Os conventos de São Paulo, Santos e o hospício de Itu teriam recebido acréscimos em suas propriedades (SILVA, 2013, p. 152-156). 
Como situou Molina (2006), duas questões de âmbito nacional se inseriam nesse momento: 0 problema da carência de mão de obra pós 1850 e a legislação repressiva às ordens religiosas. Dadas as circunstâncias políticas apresentadas na Província Carmelita Fluminense, decorrentes do fato de o governo imperial pretender gerir os bens dos conventos, os carmelitas da Ordem do Carmo de São Paulo se anteciparam e arrendaram a Fazenda Capão Alto.

No período anterior à determinação do governo imperial em subjugar a Ordem do Carmo ao Regime de Visitadores Apostólicos (1865-1889), a Fazenda Capão Alto foi visitada pelo procurador do Convento do Carmo da Corte, provavelmente em razão da própria conjuntura da Província Carmelita em 1860, para verificar como se encontravam seus bens e escravos.

Para esse momento, observou-se em uma correspondência, de 21 de abril de 1860, do Chefe de Polícia da Província do Paraná, Sebastião Conçalves da Silva, ao Delegado de Castro (PR), na qual informou que

[...] nessa data está se dirigindo a essa localidade o Reverendíssimo Frei Manoel da Natividade Azevedo - Procurador do Convento do Carmo da Corte para examinar o estado da fazenda pertencente aquele convento e recomendo-lhe que auxilie em todas as justas requisições de modo a não encontrar dificuldades (SILVA, 1860).

No Convento do Carmo de São Paulo, em 1864, viviam apenas dois frades, Prior Fr. Vicente Ferreira Alves do Rosário e Frei José de Santa Bárbara, que se responsabilizavam pelo patrimônio do convento (MOLINA, 2006).

Para o contexto de 1865 a 1869, Molina (2006, p. 109) observou que a Província Carmelita Fluminense vendeu oito propriedades rurais. Dos contratos, ao menos três foram realizados sem a licença do governo imperial e firmados após o reinício do Regime de Visitadores Apostólicos: um em 1865, três em 1866, dois em 1867 e dois em 1869. Entre ẹsses, constava o contrato referente à Fazenda Capão Alto, de 1864, considerado lesivo à Ordem do Carmo. A empresa de Bernardo Gavião, Ribeiro \& Gavião foi obrigada a desistir da transação e, através de uma composição, adquiriu 240 escravos da propriedade. Contudo, a Fazenda Capão Alto foi vendida, em 1866, a Bonifácio José Baptista por 30 contos de réis.

Do contrato de maio de 1864, Pena (1999) apontou que os carmelitas arrendaram a Fazenda Capão Alto com 241 escravos à firma paulista Bernardo Gavião, Ribeiro \& Gavião. O preço por ano contratado seria de oito contos de réis, mas receberam o adiantamento referente a três anos, 24 contos de réis. A firma de Bernardo Gavião tratou de providenciar a rápida transferência dos escravos para São Paulo. Na Fazenda Capão Alto, o sócio da firma, Camillo Gavião, encarregado 
pela transferência dos cativos, prevendo as dificuldades, tratou de mimá-los com roupas e outros donativos. Os escravos se recusavam a sair de suas terras. A situação virou caso de polícia. Após buscas, o delegado de polícia constatou armas escondidas nas senzalas. Os escravos estavam dispostos a reagir, demonstraram astúcia na resistência e em suas argumentações. Por fim, a rebelião não aconteceu e foi controlada pelas forças policiais (PENA, 1999, p. 243-244).

Para o entendimento desse drama entre escravos e arrendatário, Pena (1999) buscou em suas pesquisas as correspondências oficiais entre o Chefe da Polícia e o Presidente da Província, de abril a setembro de 1864, o relatório da Delegacia de Polícia de 1865, e o artigo publicado na Gazeta Paranaense, de 1886, anteriormente citado.

Em outra publicação, Pena (2003) referiu-se à firma paulista como Casa Comercial e Bancária de Bernardo Gavião, Ribeiro \& Gavião, como a responsável pelo episódio de arrendamento dos escravos da Fazenda Capão Alto.

Nesse contexto, insere-se uma correspondência entre o Chefe de Polícia da Província do Paraná, Manoel da Silva Mafra, enviada ao Presidente da Província, Dr. José Joaquim do Carmo, em 14 de maio de 1864, na qual afirmou que, mesmo não sendo apresentadas em forma de escritura, algumas das cláusulas estabelecidas sobre o arrendamento dos escravos só obteve por conhecimento verbal e por parte de pessoas que o leram, que sem garantir a exatidão, considerava legalmente feito:

[...] o arrendamento da fazenda Capão Alto com 241 escravos de 45 anos para menos, pela quantia de oito contos de reis anuais, por espaço de 20 anos, recebendo os carmelitas a importância de 3 anos mais ou menos adiantadas. A entrega da fazenda e escravos no prazo de dois meses, pagando a multa de três contos de reis por cada mês de retardamento. Pagarem os carmelitas a multa de um por cento ao mês do valor de cada escravo que fugir ou morrer depois da entrega, apresentada a certidão de fuga ou óbito. Os escravos só poderão ser empregados nessa e na Província de São Paulo. É lícito aos arrendatários sem pena alguma, rescindir o contrato, não tendo, porém, igual direito o Convento, sem pagar a multa de 50 contos de réis, restituindo as quantias recebidas e o prêmio de $1 \%$ ao mês. Retirar o Convento, no prazo de um ano, da fazenda toda criação de escravos não compreendidas no contrato sob pena de ficar pertencendo ao arrendatário. Terem os arrendatários a preferência na compra da fazenda e escravos, obrigando-se a obter a licença do governo imperial e devendo a compra ser feita pelas avaliações existentes ou mesmo por novas se isso convir aos arrendatários (MAFRA, 1864).

Do episódio do arrendamento envolvendo os escravos da Fazenda Capão Alto, constam outras correspondências oficiais que permitem verificar as relações sociais conflituosas. Da documentação sob custódia do Arquivo Público do Paraná, foi publicado como instrumento de 
pesquisa o Catálogo seletivo de documentos referentes aos a fricanos e afrodescendentes livres e escravos, em 2005 (ARQUIVO PÚBLICO DO PARANÁ, 2005).

Nesse Catálogo seletivo de documentos são mencionadas informações gerais para cada verbete/, documento, como as convenções adotadas em sua descrição: código de referência, autoria, destinatário, referência e descrição sucinta do teor do documento, localidade, data, a notação do documento para sua localização e o estado de conservação. No Quadro 1, os verbetes mencionados referem-se diretamente ao episódio da revolta dos escravos na Fazenda Capão Alto, com descrição para cada item documental.

Os temas missivistas dos itens documentais são referentes ao contrato de arrendamento; à escolta de escravos presos às cadeias de Castro e Curitiba, e escoltas de praças para a condução de escravos a Antonina; ao pedido de isenção de impostos solicitado por Bernardo Gavião \& Ribeiro Gavião; e à cobrança de impostos referentes à saída dos escravos da Província do Paraná. Tais fontes permitem estudar as representações e as formas de conflito desse contexto.

Quadro 1 - Documentação do Arquivo Público do Paraná, relativa ao arredamento dos escravos da Fazenda Capão Alto.

\begin{tabular}{|c|c|c|}
\hline $\begin{array}{l}\text { Número } \\
\text { Verbete }\end{array}$ & Código de referência/ Data & Descrição sucinta \\
\hline 256 & AP 0188 p. 65,11 de julho de 1864 & $\begin{array}{l}\text { Do Delegado de Polícia, Ernesto Francisco de Lima Santos, ao Presidente da Província do Paraná. Solicita- } \\
\text { ção da escolta de seis praças e um inferior para conduzir os escravos arrendados de Curitiba à Antonina. }\end{array}$ \\
\hline 257 & AP 0188 p. 64,13 de julho de 1864 & $\begin{array}{l}\text { Do Delegado de Polícia, Ernesto Francisco de Lima Santos, ao Presidente da Província do Paraná. Informa } \\
\text { que oficiou ao Comendador Manoel Antonio Cuimarães - procurador que recebesse os escravos presos na } \\
\text { Cadeia evitando, que fosse necessária a escolta com seis praças e um inferior. }\end{array}$ \\
\hline 261 & $\begin{array}{l}\text { AP } 0190 \text { p. } 243-245 \text {, de } 20 \text { e } 21 \text { de } \\
\text { setembro de } 1864\end{array}$ & $\begin{array}{l}\text { Do Inspetor da Tesouraria e Procuradoria Fiscal da Província do Paraná ao Vice-Presidente da Província dó } \\
\text { Paraná. Pedido contrário da Procuradoria Fiscal à isenção do imposto por escravos saídos da Província do } \\
\text { Paraná aos senhores Bernardo Cavião \& Ribeiro Gavião. }\end{array}$ \\
\hline 275 & $\begin{array}{l}\text { AP } 0219 \text { p. 99, de } 20 \text { de dezembro } \\
\text { de } 1865\end{array}$ & $\begin{array}{l}\text { Do Juiz de Direito Substituto, Francisco Xavier da Silva, ao Presidente da Província do Paraná. Contrato de } \\
\text { arrendamento dos escravos da Fazenda Capão Alto por Bernardo Gavião \& Ribeiro, informando que leva- } \\
\text { riam somente os escravos aptos a prestar serviços e deixariam na fazenda apenas os inválidos, juntamente } \\
\text { com pedido de isenção de impostos. }\end{array}$ \\
\hline 284 & $\begin{array}{l}\text { AP } 0251 \text { p. } 225 \text {, de } 17 \text { de janeiro } \\
\text { de } 1867\end{array}$ & $\begin{array}{l}\text { Do Chefe de Polícia da Província do Paraná ao Presidente da Província do Paraná. Resposta à Portaria que } \\
\text { pede auxílio para mandar } 23 \text { escravos comprados por Bernardo Gavião \& Ribeiro Gavião da Ordem dos } \\
\text { Carmelitas para a Província de São Paulo. }\end{array}$ \\
\hline 285 & $\begin{array}{l}\text { AP } 0253 \text { p. 08-11, de } 18 / 21 \text { de } \\
\text { janeiro de } 1867\end{array}$ & $\begin{array}{l}\text { Do Inspetor da Tesouraria da Província do Paraná ao Presidente da Província do Paraná. Sobre os impostos } \\
\text { devidos por Bernardo Gavião \& Ribeiro Gavião à Fazenda da Província do Paraná. }\end{array}$ \\
\hline 362 & $\begin{array}{l}\text { AP } 0285 \text { p. } 175-176 \text {, de } 27 \text { de } \\
\text { agosto de } 1868\end{array}$ & $\begin{array}{l}\text { Do Inspetor da Tesouraria da Província do Paraná ao Vice-Presidente da Província do Paraná. Cópia da carta } \\
\text { do encarregado da Fazenda da Província, João Mendes de Almeida, para cobrar impostos sobre a saída de } \\
\text { escravos contra a Casa Bernardo Gavião \& Ribeiro Gavião. }\end{array}$ \\
\hline
\end{tabular}

Fonte: Elaborado pela autora a partir de Arquivo Público do Paraná (2005).

No movimento de revolta na Fazenda Capão Alto foram apontados 11 escravos líderes e presos nas cadeias de Castro e Curitiba (PARANÁ, 1985). Nesse momento da revolta, alguns escravos se dispersaram e fundaram quilombos nas proximidades de Castro.

Em 1864, apesar dos esforços do poder público de Castro e Curitiba em tentar solucionar e apoiar os comerciantes paulistas, ficou constatada a burla aos cofres provinciais, com o não pa- 
gamento de impostos de saídas dos escravos no valor de, aproximadamente, 11 contos e oitocentos mil réis (PENA, 1999, p. 324).

A saída da comunidade de cativos da Fazenda Capão Alto ao interior de São Paulo foi dividida em dois grupos, provavelmente em 1867. No primeiro grupo, 50 escravos foram levados para trabalhar na construção da ferrovia que ligava as cidades paulistas de Jundiaí à Campinas, obra financiada pela própria firma Bernardo Gavião \& Cavião. O segundo grupo, com 186 escravos, foi vendido ao comendador Francisco Teixeira Vilela, de Campinas (OLIVEIRA, 2013, p. 149 e p. 164-165).

A pesquisa de Oliveira (2013) privilegiou a investigação da experiência de escravos comercializados para Campinas (SP) no período de 1850-1888, na qual constam os cativos da Fazenda Capão Alto. Para atingir seus objetivos, concentrou esforços na micro-história de três comunidades escravas, utilizando o método de ligação nominativa de fontes para seguir pessoas no tempo e entre séries documentais diferentes. Os cativos da Fazenda Capão Alto se constituíram no terceiro bloco de seus estudos com a venda para Francisco Teixeira Vilela. Num segundo momento, para esse grupo o enfoque historiográfico da autora foi para os laços de compadrio estabelecidos numa rede solidária e para as alforrias.

Entre outros aspectos, Oliveira (2013) comentou que, só em 1868, consta o registro de comercialização dos 186 escravos da Fazenda Capão Alto ao comendador Francisco Teixeira Vilela. A autora destacou que, possivelmente, a adaptação dos escravos não tenha sido fácil diante do trauma do desenraizamento e da violência do comércio interno. Antes mesmo de chegarem a Campinas (SP), o grupo sofreu novas separações. A maioria passou a residir na Fazenda Santa Maria, outros foram para as fazendas do Morro Alto e da Invernada. No geral, os cativos tiveram que se adaptar a uma nova rotina de trabalho e vivências, se integrar a outras comunidades já estabelecidas. Após seis anos da vinda deles à Fazenda Santa Maria, dois escravos, Amancio e Ladislao, fugiram. Em 1873, quando da morte do comendador Vilela, a comunidade de escravos procedentes da Fazenda Capão Alto era de 123 cativos. Eram 54 mulheres, sendo 39 solteiras e 15 que eram ou já haviam sido casadas. O número de homens era de 69 e, desses, apenas nove eram casados ou viúvos. Muitos dos casais viveram em união consensual (OLIVEIRA, 2013, p. 158, p. 166-167 e p. 174).

Numa outra ênfase, estudos de Ribeiro (2012) comparam as formas de riqueza e financiamentos das atividades produtivas de Campinas entre 1850-1873, utilizando fontes documentais do poder judiciário e cartorial, recenseamentos populacionais e almanaques. 
Ribeiro (2012, p. 16) faz indagações sobre a firma Gavião, Ribeiro \& Gavião. Primeiramente, de quais recursos se utilizaram para transferir ou vender os escravos da Fazenda Capão Alto para Francisco Teixeira Vilela. A autora apontou que, em 1860, a Casa Bancária de Bernardo Avelino Gavião Peixoto era considerada a maior em poder de influência junto à Corte imperial. Ao final dessa argu-' mentação, a autora problematizou com a pergunta: "Ao que tudo indica eram a mesma firma ou Bernardo Gavião atuava na Casa Bancária e na firma Bernardo Gavião, Ribeiro \& Gavião?".

Para esse contexto, observou-se que a Companhia Paulista de Estrada de Ferro Jundiaí a Campinas foi inaugurada em 1868, e o desembargador Bernardo Avelino Gavião Peixoto integrava a diretoria provisória (MOLINA, 2006).

Quando chegaram os escravos da Fazenda Capão Alto, em 1868, Francisco Teixeira Vilela recolheu o imposto de meia sisa ${ }^{5}$ e pagou a quantia devida à Coletoria de Rendas de Campinas a importância de trinta mil réis por escravo, totalizados em cinco contos quinhentos e oitenta mil réis (RIBEIRO, 2012, p. 16).

O estudo de Oliveira (2013) registrou a composição das faixas etárias dos escravos comprados da Fazenda Capão Alto por Francisco Teixeira Vilela. O Quadro 2 demonstra que a composição mais expressiva em número e idade foi a da faixa etária de 0 a 14, com um total de 87 , dos quais 46 homens e 41 mulheres. A de menor composição foi a faixa etária acima dos 45 anos, com um total de 28 escravos, sendo 10 homens e 18 mulheres.

Quadro 2 - Faixa etária dos escravos da fazenda Capão Alto comprados por Francisco Teixeira Vilela.

\begin{tabular}{|c|c|c|c|}
\hline Faixa Etária & Homem & Mulher & Total \\
\hline $0-4$ & 10 & 15 & \multirow{3}{*}{87} \\
\hline $5-9$ & 19 & 09 & \\
\hline $10-14$ & 17 . & 17 & \\
\hline 15-19 & 05 & 06 & \multirow{3}{*}{34} \\
\hline $20-24$ & 11 & 03 & \\
\hline $25-29$ & 03 & 06 & \\
\hline $30-34$ & 06 & 10 & \multirow{3}{*}{37} \\
\hline $35-39$ & 07 & 04 & \\
\hline $40-44$ & 05 & 11 & \\
\hline $45-49$ & 02 & 08 & \multirow{3}{*}{28} \\
\hline $50-54$ & 06 & 08 & \\
\hline $55 \mathrm{ou}+$ mais & 02 & 02 & \\
\hline Total & 87 & 99 & 186 \\
\hline
\end{tabular}

Fonte: Coletoria de Rendas de Campinas, Livro 43 (Centro de Memória - Unicamp apud OLIVEIRA, 2013, p. 166).

5 A sisa era o imposto cobrado, para a saída ou entrada, sobre qualquer transação de compra e venda, inclusive de escravos. 0 valor era de $5 \%$ referente ao valor total da mercadoria (ARQUIVO PÚBLICO DO PARANÁ, 2005, p. 18). 
Na Fazenda Santa Maria de Francisco Teixeira Vilela, 10 dos escravos vindos da Capão Alto ocuparam ofícios especializados. Foram seis mulheres dedicadas ao serviço doméstico e ao trabaIho de cozinheira, e quatro homens que trabalharam como tropeiro, carpinteiro e em serviços fora da fazenda (OLIVEIRA, 2013, p. 174).

Para os escravos da Fazenda Santa Maria, Francisco Teixeira Vilela propiciou o ensino de música, com professor contratado, e ainda manteve um contrato anual com médico e clínica para prestar assistência aos escravos (RIBEIRO, 2012, p. 17). Nessa fazenda é que se concentrou o maior número de escravos vindos da Fazenda Capão Alto.

Para o inusitado aspecto musical entre os escravos, Oliveira (2013) registrou a formação de uma banda musical entre os cativos de Vilela, dirigidos pelo maestro Sabino Antonio da Silva, vindo do Rio de Janeiro. A banda dos "escravos-músicos" apresentou-se algumas vezes em Campinas (SP). Para a inauguração do trecho da estação de estrada de ferro da Companhia Paulista de Estradas de Ferro, os músicos se apresentaram por duas vezes, na cerimônia oficial e na reunião de convidados, conforme relatado no Almanak de Campinas de 7873, sob o título Música de Pretos. Curiosamente, nessa estrada de ferro, no sentido inverso, se concentrou o primeiro grupo de escravos vindos da Fazenda Capão Alto (RIBEIRO, 2012). Para a inauguração da estação, a banda executou a peça musical A estrada de ferro, composição do maestro Santana Comes, irmão do compositor Antonio Carlos Comes (RIBEIRO, 2015, p. 552).

Posteriormente, quando da morte e abertura do inventário de Francisco Teixeira Vilela, foi constatado que as dívidas, os créditos hipotecários e comerciais eram superiores ao seu acervo patrimonial. Da composição do inventário post-mortem, constou a concentração de sua riqueza em escravos: 452 cativos, mais 13 ingênuos em plantações de café, incluindo terras e benfeitorias. No encerramento do acervo hereditário pro-indiviso de Francisco Teixeira Vilela, em 1892, a Fazenda Santa Maria foi vendida para a Companhia Rural do Brasil (RIB́EIRO, 2012, p. 16-21).

\section{Quilombos e Comunidades de Remanescentes de Quilombos (CRQs)}

Por vezes, na historiografia tradicional paranaense observou-se a apropriação descontextualizada do termo "quilombo da Capão Alto" referindo-se aos escravos da Fazenda Capão Alto, seja por sua vivência libertária em comunidade ou pelo momento da revolta de 1864. 
Diante do descortinamento das Comunidades de Remanescentes de Quilombos (CRQs), concomitante ao processo de inclusão sociocultural e de inclusão do ensino da história e cultura afro-brasileira nas escolas brasileiras, é significativo fazer uma leitura crítica quando da utilização dos termos quilombo e Comunidades de Remanescentes de Quilombos (CRQs).

O termo quilombo utilizado no Brasil remete à ideia de uma comunidade de escravos fugidos, da etimologia quimbundo como aldeia, ao local que viviam os calhambolas, da legislação colonial como foco de resistência, de escravos fugidos e isolados. Na história, o termo é redimensionado e ultrapassa o binômio fuga-resistência para considerar as variadas situações da ocupação territorial no contexto atual. A noção de quilombo não é restrita às fugas ou refúgios e, sim, à formação dos grupos familiares. As diversas trajetórias dessas comunidades trazem suas particularidades regionais e seu contexto histórico. Hoje, os descendentes desses grupos demandam por seu reconhecimento, direito às terras e ressignificação de seus valores culturais e simbólicos (CARVALHO \& LIMA, 2013).

Nos preceitos inscritos na Constituição de 1988, do Ato das Disposições Constitucionais Transitórias da Constituição Federal (ADCT), os Artigos n 68, 215 e 216, respectivamente, instituem o reconhecimento das propriedades de remanescentes das comunidades de quilombos; proteção e valorização das manifestações culturais populares na dimensão das diversidades étnicas e regionais; e constituição enquanto patrimônio cultural brasileiro a se preservar como bens materiais e/ou imateriais. A Lei $n^{\circ} 10.678 / 2003$ trata da criação da Secretaria Especial de Políticas de Promoção da Igualdade Racial, no âmbito da qual, posteriormente, formou-se o Grupo de Trabalho Interministerial (CTI), para traçar as diretrizes gerais ao Programa Nacional de Quilombos. Esses são al guns dos aspectos das conquistas enquanto políticas públicas voltadas ao reconhecimento social dessas comunidades.

Para um conceito antropológico, geográfico e histórico, esses preceitos constitucionais das Comunidades de Remanescentes de Quilombos (CRQs) se dilatam para questões voltadas à expressão de sua territorialidade e identidade étnica, ao reconhecimento de seus direitos sociais e à preservação de bens de natureza material e imaterial.

As $C R Q$ s estão em áreas que trazem as marcas da história da resistência negra à escravidão brasileira e são certificadas pela Fundação Cultural de Palmares. As comunidades são caracterizadas por suas especificidades culturais com ancestralidade negra e por praticarem uma agricultura fundamentada nas formas tradicionais de manejo e uso comum da terra, com formas de cooperação entre às famílias. 
Na região de Castro (Paraná), na microrregião de Ponta Grossa, segundo o Grupo de Trabalho Clóvis de Moura (2015) e ITCC (2008), estão as comunidades certificadas, as CRQs, da Serra do Apon, Mamãs, Limitão, com descendentes de escravos fugidos das Fazendas Capão Alto, e a CRQ do Tronco, com descendentes de escravos fugidos da Fazenda Cunhaporanga.

De maneira concisa constatou-se, conforme disposto no levantamento dos dados do ITCC (2008), que a CRQ da Serra do Apon foi dividida em quatro núcleos: Paiol do

As comunidades certificadas, as CRQs, da Serra do Apon, Mamãs, Limitão, com descendentes de escravos fugidos das Fazendas Capão Alto, e a CRQ do Tronco, com descendentes de escravos fugidos da Fazenda Cunhaporanga. Meio, Faxinal do São João, Santa Quitéria e Lagoa dos Alves, com 31 famílias e 103 habitantes. A CRQ de Mamãs apresentava os núcleos certificados como município de Castro, com dois na fronteira do município de Cerro Azul: Imbuial, Água Morna (Castro), Pinhal Crande (Castro/Cerro Azul), Ribeirão do Meio (Castro/Cerro Azul), com 25 famílias e 96 habitantes. A CRQ do Limitão não apresentou núcleos e era integrada por 26 famílias e 95 habitantes.

As Comunidades de Remanescentes de Quilombos (CRQs) da região de Castro, com seus descendentes de escravos da Fazenda Capão Alto e Cunhaporanga, sugerem novas pesquisas direcionadas à história, às memórias dos mais idosos com traços das recordações passadas por seus antecessores e das vivências no ambiente revisitado das fazendas.

\section{Referências}

\section{Fontes primárias:}

AUTO DE VIOLÊNCIA sobre os vizinhos moradores de fundos para retomarem a servidão do Maracanã. 01/03/1798. Cópia do Arquivo do Estado de São Paulo. Ordem B0317 D1. Acervo Documental Prof. ${ }^{2}$ Elizabete Alves Pinto. Caixa 2. Doc. 1. Centro de Documentação e Pesquisa em História. Universidade Estadual de Ponta Grossa.

GAZETA PARANAENSE. Publicação diárià $n^{\circ}$. 218. Oś escravos do Capão Alto. Curitiba, 30 de setembro de 1886. Biblioteca Nacional Digital. Disponível em: <http://memoria.bn.br/pdf/242896/ per242896_1886_00218.pdf>. Acesso em: ago. 2015.

INSCRIÇÃO LIVRO TOMBO II Nº. 80, PROCESSO Nº. 82/81, DE 26 DE NOVEMBRO DE 1983. Registro do tombamento estadual da Fazenda Capão Alto, de Castro (PR). Secretaria de Estado da Cultura. Coordenadoria do Patrimônio Cultural. Curitiba (PR). 
LISTAS NOMINATIVAS 1801-1830 DA VILA DE CASTRO (PR). Cópia xerografada do Arquivo do Estado de São Paulo. Acervo Documental Prof. ${ }^{a}$ Elizabete Alves Pinto. Centro de Documentação e Pesquisa em História. Universidade Estadual de Ponta Grossa.

MAFRA, Manoel da Silva [Chefe de Polícia da Província do Paraná]. Carta/ofício a José Joaquim do Carmo [Presidente de Província do Paraná]. Livro de correspondência de autoridades. Cidade, 14 de maio de 1864. [AEPR - Códice 0537. p. 71 a 75]. Transcrição do manuscrito. Pasta Fazenda Capão Alto. Museu do Tropeiro, Castro (PR).

MÜLLER, Daniel Pedro. Ensaio d'um Quadro Estatístico da Província de S. Paulo em 1836. São Paulo: Typographia de Costa Silveira, 1838. Biblioteca Brasiliana Guita e José Mindlin. Universidade de São Paulo. Disponível em:<https://digital.bbm.usp.br/handle/bbm/7101>. Acesso em: mar. 2018.

OFICIO PARA O DR. FRANCISCO LEANDRO DE TOLEDO RENDON, OUVIDOR DE PARNACUÁ. 15/07/1785. Publicação oficial de Documentos interessantes para a história e costumes de São Paulo. Ofícios do General Francisco da Cunha Menezes (Governador da Capitania). 1782-1786. São Paulo: Departamento de Arquivo do Estado de São Paulo/Secretaria de Educação, 1961. v. 85. Biblioteca Digital da Universidade Estadual Paulista. Disponível em: <http://bibdig.biblioteca.unesp.br/handle/10/59/ browse?type=title>. Acesso em: jan. 2015.

SILVA, Sebastião Gonçalves da - Chefe de Polícia da Província do Paraná ao Delegado de Castro. Ofício. Livro de correspondências enviadas a autoridades. 21 de abril de 1860. p. 46. Transcrição do manuscrito. Pasta Fazenda Capão Alto. Museu do Tropeiro, Castro (PR).

\section{Outros materiais bibliográficos:}

ARQUIVO PÚBLICO DO PARANÁ. Catálogo seletivo de documentos referentes aos a fricanos e afrodescendentes livres e escravos. Curitiba: DEAP, 2005. Disponível em: <http://www.arquivopublico.pr.gov.br/arquivos/ File/pdf/catalogo afro.pdf>. Acesso em: jan. 2015.

ARROYO, Leonardo. Igrejas de São Paulo. Introdução ao estudo dos templos mais característicos de São Paulo nas suas relações com a crônica da cidade. 2. ed. rev. São Paulo: Companhía Editora Nacional, 1966. (Coleção Brasiliana, v. 331). Disponível em: <http://www.brasiliana.com.br/brasiliana/colecao/ obras>. Acesso em: jun. 2015.

BASSANEZI, Maria Silvia C. Beozzo. (Org.). Dados demográficos: São Paulo do passado 1836/l. Campinas: Nepo/Unicamp, 1998. Disponível em: <http://www.nepo.unicamp.br/publicacoes/censos.html>. Acesso em: jul. 2015.

BRUNO, Ernani Silva. História e tradições da cidade de São Paulo. Rio de Janeiro: Livraria José Olympio, 1953. v. 2. (Coleção de Documentos Brasileiros, n. 80a).

CARVALHO, Robertá Monique Amancio de; LIMA, Gustavo Ferreira da Costa. Comunidades quilombolas, territorialidades e a legislação no Brasil: uma análise histórica. Política \& Trabalho, João Pessoa, n. 39 , p. 329-346, out. 2013. Disponível em: <http://periodicos.ufpb.br/ojs/index.php/politicaetrabalho/article/view/12745/9962>. Acesso em: maio 2015. 
GRUPO DE TRABALHO CLÓVIS MOURA. Disponível em: <http://www.gtclovismoura.pr.gov.br>. Acesso em: ago. 2015.

GUTIÉRREZ, Horacio. Fazendas de gado no Paraná escravista. Topoi, Rio de Janeiro, v. 5. n. 9, p. 102-127, jul./dez. 2004. Disponível em: <http://www.scielo.br/pdf/topoi/v5n9/2237-1.01X-topoi-5-09-00103. pdf>. Acesso em: jul. 2015.

INSTITUTO DE TERRAS, CARTOGRAFIA E GEOCIÊNCIAS. Terra e cidadania. Terras e territórios quilombolas. Grupo de trabalho Clóvis Moura. Relatório 2005-2008. Curitiba: ITCG, 2008.v. 3.

MELLO, Kátia Andréia Vieira de. Comportamentos e práticas familiares nos domicílios escravistas de Castro (1824-1835) segundo as listas nominativas de habitantes. Dissertação (Mestrado em História) - Universidade Federal do Paraná, Curitiba. 2004.

MOLINA, Sandra Rita. A morte da tradição: a Ordem do Carmo e os escravos da Santa contra o Império do Brasil (1850-1889). Tese (Doutorado em História Social) - Universidade de São Paulo, São Paulo. 2006.

OLIVEIRA, Joice Fernanda de Souza. Forasteiros no oeste paulista: escravos no comércio interno de cativos e suas experiências em Campinas, 1850/1888. Dissertação (Mestrado em História) - Universidade Estadual de Campinas, Campinas. 2013.

PARANÁ. Secretaria de Estado da Cultura. Coordenadoria do Patrimônio Cultural. Fazenda Capão Alto. Curitiba; Castro: SECE; Kluger Artes, 1985. [Edição corrigida. Reedição da Cooperativa Central de Laticínios do Paraná Ltda]. (Cadernos do Patrimônio, Série Estudos, n. 1).

PEDRAS, Beatriz Junqueira. Uma leitura do I Livro de Tombo do Convento do Carmo em Salvador: Contribuição à construção histórica da Ordem dos Carmelitas na Bahia-Colonial. Dissertação (Mestrado em Ciência da Informação) - Universidade Federal de Minas Ceraï, Belo Horizonte. 2000.

PENA, Eduardo Spiller. Ojogo da face, a astúcia escrava frente aos senhores è lei na Curitiba Provincial. Curitiba: Aos Quatro Ventos, 1999.

Burlas à lei e revolta escrava no tráfico interno do Brasil Meridional - século XIX [resumo]. In: ENCONTRO ESCRAVIDÃO E LIBERDADE NO BRASIL MERIDIONAL, 1., 2003, Castro. Anais... [S.I.]: Boletim de História Demográfica, 2003. Disponível em: <http://historia demografica.tripod.com/bhds/ bhd30/bhd30.htm>. Acesso em: jan. 2015.

PINTO, Elisabete Alves. Vila de Castro: população e domicílios (1801 - 1830). Tese (Doutorado em História Demográfica) - Universidade Federal do Paraná, Curitiba. 1992.

RIBEIRO, Maria Alice Rosa. Família Teixeira Vilela e o padrão de riqueza e de endividamento: Campinas/ São Paulo, 1850-1873. Núcleos de Pesquisa. Hermes \& Clio. São Paulo: FEA/USP, 2012. Disponível em: <http://200.144.189.47/feaecon/media/fck/File/MariaAliceRosaRibeiro_FamiliaTeixeiraVilela.pdf>. Acesso em: jul. 2015. 
Notas de Pesquisa

História Econômicag

Demografia Histónee

Parte 2

DOI: $10.20396 /$ resgate.v26i1.8649585

RIBEIRO, Maria Aljce Rosa. Riqueza e endividamento na economia de plantation açucareira e cafeeira: a família Teixeira Vilela-Teixeira Nogueira, Campinas, São Paulo, século XIX. Estudos Econômicos, São Paulo, v. 45, n. 3, p. 527-565, jul./set. 2015. Disponível em: <http://www.revistas.usp.br/ee/article/ view/56837>. Acesso em: nov. 2015.

ROSAS, José Pedro Novaes. A fundação da cidade de Castro. Curitiba: Vicentina, 1972.

SILVA, Leandro Ferreira Lima da. À sombra da última ruína' regalismo e gestão material na Província de Nossa Senhora do Carmo do Rio de Janeiro. Revista Angelus Novus, São Paulo, v. 4, n. 6, p. 143-162, 2013. Disponivel em: <http://www.usp.br/ran/ojs/index.php/angelusnovus/article/view/235>. Acesso em: set. 2015.

WERNET, Augustin. Crise e definhamento das tradicionais ordens monásticas brasileiras durante o século XIX. Revista do Instituto de Estudos Brasileiros, São Paulo, n. 42, p. 115-131, jan.1997. Disponível em: <http://www.revistas.usp.br/rieb/article/view/73464>. Acesso em: jul. 2015.

190

Resgate-Rev. Interdiscip. Cult., Campinas, v. 26, n.1 [35], p. 173-190, jan./jun. 2018-e-ISSN: 2178-3284 